\title{
El viaje de Marina Abramovic y Lady Gaga a través de la hipermodernidad: "Si compartes tus fans, te doy capital simbólico".
}

\author{
Asunción BERNÁRDEZ RODAL \\ Facultad de Ciencias de la Información \\ Universidad Complutense de Madrid \\ asbernar@ucm.es
}

Recibido: 04.11.2013

Aceptado: 15.11.2013

\begin{abstract}
RESUMEN
Este texto parte de un hecho puntual: la colaboración artística planteada durante el año 2013 entre la performer Marina Abramovic y Lady Gaga y que podemos leer como una metáfora de lo que está ocurriendo en el Arte y en la cultura popular en estos momentos en los que Internet 2.0 ha hecho posible la participación de los receptores en la creación de los productos culturales. La consecuencia fundamental es que se ha producido un borrado definitivo de fronteras entre la alta cultura y la cultura mediática, causada sobre todo por el hecho de que el público pasa a ser considerado parte del proceso creativo de los textos artísticos o mediáticos que son la base del intercambio simbólico en el mundo contemporáneo. Estudiar las consecuencias que pueda tener todo esto para el feminismo o la representación de las mujeres en el arte y en los medios, será uno de los objetivos de nuestro texto.
\end{abstract}

Palabras clave: Arte, Feminismo, Marina Abramovic, Lady Gaga, Hipermodernidad.

The trip of Marina Abramovic and Lady Gaga through the hypermodernity: "If you share your fans, I'll give you symbolic capital".

\begin{abstract}
This text is part of a single event: the artistic collaboration between the performer Marina Abramovic and Lady Gaga in 2013. We can read this collaboration as a metaphor about the relation between the art and the popular culture in a time in which Internet 2.0 has made possible the participation of receptors in the creation of cultural products. Therefore, the borders between high culture and media culture have been erased, due to the public become part of the creative process of art or media texts, which are the underlie of symbolic exchange in the contemporary world. The objective of the text is study the possible consequences of all these changes for feminism and the women's representation in art and the media.
\end{abstract}

Key words: Art, Feminism, Marina Abramovic, Lady Gaga, Hipermodern. 


\section{INTRODUCCIÓN}

Durante el pasado mes de septiembre apareció en la prensa la noticia de que la performer Marina Abramovic iba a participar en la promoción del próximo disco de Lady Gaga llamado ARTPOP que saldrá a la venta durante el mes de noviembre de 2013. Al mismo tiempo, Lady Gaga rodaba un vídeo promocional de la técnica de meditación Abramovic, para apoyar la recaudación de fondos para la fundación del Marina Abramovic Institut en Huston, Nueva York. Todo ello es además anunciado en la fiesta anual de fines de verano que el director de escena Robert Wilson celebra en su fundación de Long Island donde reúne a distintas celebridades y artistas.

A partir de este hecho puntual, este artículo pretende analiza las claves de relación entre ambas artistas que pertenecen a entornos culturales diferentes: la cultura pop y el Arte, tomándolas como metáfora de lo que está ocurriendo en la hipermodernidad: el uso del público interactivo en la construcción de los productos culturales, en una sociedad del entretenimiento generalizada que ha echado por tierra las fronteras que podían seguir existiendo entre la alta cultura y la cultura de los medios de comunicación.

En el contexto complejo de dura competición por la atención del público, Lady Gaga y Marina Abramovic se han saltado la convención que dice que la performance pertenece a la alta cultura y los videoclips y las canciones pop a la cultura mainstream. Cuánto ganan o pierden una $\mathrm{u}$ otra en profundidad o en banalidad respecto a su propio trabajo, es una cuestión que no tiene sentido plantearse en un mundo donde los y las artistas luchan por ganar unos segundos de atención sobre sus obras en un universo hipersaturado de textos. Cualquier artista desearía que sus obras fueran conocidas por tanto público como al que llegan los videos y canciones de Lady Gaga, sobre todo, porque eso -tal como ha declarado Marina Abramovic- les proporciona la libertad económica que se necesita para emprender costosos proyectos artísticos, dado que hoy en día el artista casi nunca es ese genio que sólo necesita la soledad de su estudio para crear. Y no es una cuestión de reconocimiento, sino de poder conseguir unos recursos para llevar adelante obras colectivas y costosas que necesitan de un entramado de producción profesionalizada.

A Lady Gaga le sobran fans y seguidores. Cuenta con recursos más que suficientes para llevar adelante sus propias creaciones, y puede incluso participar en una gran cantidad de eventos de forma altruista. Sin embargo, no desprecia la relación con una gran artista de la performance como Marina Abramovic porque, en el difuminado de fronteras que se está produciendo entre la baja y la alta cultura, esta artista sigue 
teniendo capital simbólico"1 que diría Bourdieu. Una relación que surge en un momento en el que las industrias culturales reconocen el poder de influencia de la imagen pública de los ídolos a través de todas las formas virales de comunicación. Esto explica que la prensa generalista señale como elemento significativo que Lady Gaga y Marina Abramovic se apoyen mutuamente: la primera participando en el proyecto de creación en Nueva York del "Marina Abramovic Institute" dedicado a "preservar la performance" solicitando a través de una web de crowdfunding el apoyo económico necesario, y la segunda colaborando con el disco que la cantante sacará a la calle el próximo mes de noviembre con el significativo título de 'Artpop'.

Las alianzas entre artistas masculinos (el caso más conocido es Andy Warhol) y estrellas mediáticas viene produciéndose desde hace más de cincuenta años, sin embargo, no ha sido tan común ni tan visible que se produzca entre mujeres. El periodista que cuenta la relación entre las dos creadoras titula su texto de forma muy significativa: "Lady Gaga y Marina Abramovic, la extraña pareja". Son una extraña pareja, sobre todo porque son creadoras que en principio parecen provenir y proyectarse en áreas antagónicas: la cultura mediática y el mundo del Arte, si es verdad que esa distinción sigue teniendo sentido en un universo donde todo aquello que puede ser etiquetado con la palabra "cultura" es susceptible de ser mezclado, alterado y consumido a gusto de los receptores que, a su vez, han sido declarados como parte activa del proceso creador en sí mismo.

\section{LOS PÚBLICOS Y LA PRODUCCIÓN CULTURAL: DISTORSIONES ENTRE BAJA/ ALTA CULTURA.}

La conjugación del Arte con mayúsculas y la comercialidad, sobre todo si está asociada a los medios de comunicación, ha levantado siempre sospechas en las élites culturales, que a lo largo del siglo XX, insistieron en la idea de Walther Benjamin (1989) que ante la reproducción técnica y masiva, las obras perderían su "aura", su

${ }^{1}$ Este concepto se refiere a los estudios de Bourdieu (1991) sobre la sociología de la cultura, en los que argumenta que las clases que tienen el poder económico, se legitiman a través de los aspectos simbólicos que tiene el consumo. En nuestras sociedades, donde la clase económica dominante es la burguesa, la estética más legitimada es la que esa clase refrenda como "alta cultura". Una obra de arte o una artista, aumentará de valor en la medida en que asume las reglas que ese tipo de cultura marca como válidas. El poder cultural o simbólico es un tipo de poder que acumulan individualmente las personas en la medida en que puede acumular cualificaciones intelectuales producidas por los medios culturales en los que se forma: el colegio al que asiste, los títulos que consigue o los productos culturales que consume.

${ }^{2}$ Vid. El País, 6 de septiembre de 2013. 
principio de originalidad e individualidad. Pero esas élites se olvidaron a menudo de que Benjamin decía también otra cosa: que esa pérdida de "aura" podría suponer un principio liberador para la clase obrera, que podría por fin hacerse con los recursos necesarios para la creatividad, que hasta ese momento estaba en manos de la clase burguesa. Así, el cuestionamiento del principio de originalidad artística, tendría como consecuencia la democratización del arte. Casi un siglo después, las cosas han cambiado mucho. Sobre todo porque ha ocurrido algo que Benjamin, alrededor de los años treinta del siglo pasado, no podía ni siquiera intuir: la eclosión de las Nuevas Tecnologías de la Información, que han transformado la cultura (y la economía) más allá de lo que era previsible que lo hicieran los medios de masas tradicionales como la prensa escrita, el cine o incluso la televisión.

Por otra parte, tampoco podemos hablar hoy de que la producción artística o cultural pertenece a la "clase burguesa", ya que eso supondría ignorar todo el debate producido a partir de la II Guerra Mundial, momento a partir del cual, la preocupación social no está tanto en solucionar los problemas que puedan afectarle a las personas dependiendo de la clase a la que pertenecen, sino en definir individualmente qué somos y cómo podemos reforzar nuestra identidad personal. De hecho, el concepto de "identidad" tanto personal como colectiva, se ha convertido en los últimos años en el objeto de la filosofía y la teoría sociológica. En este contexto, la producción de bienes culturales y simbólicos se ha puesto en gran medida en función de la potenciación del consumo individual por parte del mundo publicitario, que ha basado su estrategia persuasiva en afianzar la seguridad personal reforzando "quienes somos", ciegos en la fe posmoderna de que "podemos construirnos" en identidades elegidas y diseñadas a base de voluntad individual, y también de consumo.

En esta búsqueda de la "identidad" los medios nos interpelan de forma identitaria: como mujeres, como hombres, como pertenecientes a una clase, a una etnia, a una profesión o a un determinado colectivo. Los medios convencionales como la televisión, el cine o la prensa siguen teniendo un papel fundamental en el proceso, pero además, en los últimos años las redes sociales han venido a prolongar esa fantasía colectiva de la exaltación de la individualidad, proyectando la imagen que construimos sobre nosotros mismos en el territorio público. El poder de ser y de representarse como identidad personal resulta ahora amplificado en las redes sociales, que exigen que participemos con nuestra individualidad en un proceso colectivo en el que la adoración a ciertos ídolos resulta un elemento aglutinante fundamental. Somos sujetos individuales, pero el dios Internet exige el tributo de la participación en la adoración a los ídolos, sean estos cantantes, performans, causas políticas o ecológicas. No es que todo "sea lo mismo", pero todo exige una actividad participativa, una atención permanente y constante hacia los otros. 
Un ejemplo de todo esto lo encontramos en plataformas como Facebook, Twitter, Digg, YouTube, que han revolucionado la publicidad y el marketing en la actualidad. Internet ha ido más allá de ser, como se creía en sus orígenes, una plataforma de información, sino que se ha convertido en una plataforma de influencia social (Richard, H. Rohm, A. and Crittenden, V. L. (2011: 8), en la que todos los poderes sociales (económico, político, religiosos, etcétera) deben tener una presencia activa si quieren seguir actuando como tales. El público forma parte del proceso de creación de contenidos publicitarios de un determinado producto, en un proceso de integración que ha venido desarrollándose con la web 2.0, de tal forma que el epicentro del llamado ecosistema de los medios está centrado en la experiencia de los consumidores.

En este contexto, la creación de objetos artísticos y culturales se ha convertido en un elemento sustancial y fundamental al sistema. Tenemos la sensación de que de que el Arte y la cultura no es sólo lo que está en los museos, los auditorios o en los teatros porque todo intenta ser "de diseño" y "original", al mismo tiempo de que se general la ilusión de que el arte está por todas partes y que surge de una forma natural y espontánea". Sin embargo, hay una profunda falsedad en esta idea: la producción cultural no tiene nada de "democrática" o "proletaria" que diría Benjamin. La producción cultural está hoy en manos de una nueve élite que, eso sí, pueden no coincidir con las clases altas. El proletariado es en realidad un "infoproletariado" o "proletario de la información"3 que interviene en los procesos de producción de valores simbólicos. Por ejemplo, en el marketing y la publicidad o en cualquier producción audiovisual actúan personas especializadas, que pueden tener o no una cultura universitaria, que pueden tener más o menos recursos económicos, pero que desde luego conocen el mundo de la creatividad asociada a los productos audiovisuales.

Y pese a todo, algo ha cambiado: Internet se ha llenado de contenidos producidos por gente no profesional. El amauterismo ha pasado a formar parte de la estética aceptable en nuestro tiempo devaluando el trabajo profesionalizado: cualquiera con una cámara puede ser periodista, cualquiera puede llenar el tiempo de un informativo de forma poco especializada o puede llegar a tener más de un segundo de gloria en youtube al producir un vídeo simpático. Hoy las fronteras entre los especialistas y los aficionados son muy borrosas, hasta el punto de no poder separar de forma radical lo

\footnotetext{
${ }^{3}$ Vid. el concepto popularizado por Franco Berardi, Bifo, en el que alude a la idea de que hoy en día hay un elemento común a la mayoría de los trabajadores: el trabajar con la información, y aunque aparentemente puede ser un trabajo especializado, al mismo tiempo, ha convertido en precario ese trabajo por el abaratamiento de salarios, la exigencia de trabajar sin horarios ni límites temporales, por el auto-empleo etcétera, lo que determina las condiciones de precariedad de los trabajadores en la vida contemporánea.
} 
que pertenece al mundo de los medios de comunicación, a la cultura mainstream o a la "cultura de las élites".

En este proceso de inclusión de diferentes textos artísticos en un debate general sobre el arte, que sigue manteniendo por cierto la postura de que existe en tanto tal, las mujeres creadoras están tejiendo una historia particular. Descentradas una vez más del panorama artístico general que sigue siendo masculino, buscan alianzas y formas de estar en el debate artístico aprovechando las posibilidades que dan no sólo las Nuevas Tecnologías de la Información, sino la nueva configuración de la relación existente entre creadores/as y públicos. Esta nueva relación es la base de la hipermodernidad en la que lo que caracterizaba el fenómeno 'fan', propio hasta hace poco tiempo de la música pop-rock, está afectando a las producciones etiquetadas como "alta cultura".

\section{LA CULTURA COMO MUJER: "ALTA CULTURA"/ "CULTURA MEDIÁTICA"}

Las élites culturales desconfiaron de los medios de comunicación masiva (al menos hasta el desarrollo de los Cultural Studies en Inglaterra), y también del arte hecho por las mujeres, que salvo en casos excepcionales, no ha dejado de representar sólo un tanto por ciento mínimo de todo el negocio artístico ${ }^{4}$. Andreas Huyssens (2002) en su obra "La cultura de masas como mujer: lo otro del modernismo" señalaba cómo las referencias a la cultura de masas a principios del siglo XX eran significativamente femeninas, asimilando esa forma de producción cultural con la pasividad, la falta de iniciativa o el conservadurismo. Posteriormente la cultura mediática fue perdiendo ese matiz después de la II Guerra Mundial, debido sobre todo según Huyssens (2002:120) “... a la presencia visible y pública de las artistas mujeres en el arte elevado y la irrupción de nuevos tipos de mujeres realizadoras y productoras en la cultura de masas lo que volvió obsoleto el antiguo recurso de caracterizarla a partir de atribuciones de género. Lo paradójico, era además que la asimilación de la cultura de masas a lo femenino dependía de la exclusión real de las mujeres de la alta cultura y de sus instituciones." Por eso afirma Huyssens (2000: 95) que las mujeres y las masas fueron las que "golpearon las puertas" a principios del siglo XX de una cultura dominada por hombres.

Por otra parte, en el proceso de la extensión del capitalismo propio de los años que siguieron a la II Guerra Mundial, la expansión del consumo, especialmente asociado a los hogares, tuvo una importancia estructural, fortalecido en un primer momento con

\footnotetext{
${ }^{4}$ La Asociación de Mujeres en las Artes Visuales ha elaborado un informe que puede consultarse en http://www.m-arteyculturavisual.com/wp-content/uploads/2013/03/PROFESIONALES-TODOS.pdf
} 
la televisión y posteriormente con los ordenadores personales e Internet, que han ido cambiando de forma radical los hábitos culturales y expectativas de las personas. Susan Buck-Morss (2004: 227) dice que lo que ocurre es que se produce un efecto compensatorio: lo que se le roba al trabajador de lo que produce, se le devuelve como consumidor. En el caso de las mujeres, esa compensación tiene un efecto concreto ya que el espacio doméstico se convierte en el lugar donde se produce esta reificación, de tal forma que "una de las grandes ironías de este siglo es el hecho de que el socialismo traicionó los intereses de las mujeres al desdibujar el espacio doméstico mientras que el capitalismo lo hizo mediante su idealización" (Susan Buck-Morss, 2004).

Las mujeres se colocaron así en el centro del cambio sociológico y simbólico producido a partir de los años cincuenta. La cultura de masas se cuenta a través de la metáfora de lo femenino: son objetos y al mismo tiempo consumidoras, mientras que la parte más "activa" y productiva del sistema les está vedada. Esta estrategia no pasó desapercibida a algunas teóricas y activistas feministas, que desde el principio del desarrollo de Internet se propusieron intervenir de forma activa en el proceso de evolución del mundo de la información que estaba teniendo lugar desde principios de los años ochenta. El "Ciberfeminismo" de los años ochenta y noventa (Bernárdez, A. 2005), es un ejemplo de cómo las mujeres feministas organizan sus prácticas y desarrollan su teoría política para conseguir el objetivo práctico de estar presentes en un desarrollo tecnológico que, de entrada, las excluye.

Otro ejemplo de la nueva posición que toman las mujeres frente a los cambios producidos en las sociedades posmodernas es la posición que toman algunas creadoras frente al Arte cuestionando sus bases estructurales de las que están excluidas. El ejemplo siguiente pudiera parecer un simple anécdota por lo que pudiera tener de frívolo o incluso azaroso: la primera vez que se «representa» públicamente la relación entre la nueva museística y la presencia activa de las mujeres en el mundo del arte, no se debió al feminismo militante, ni a las artistas, ni a las conservadoras o trabajadoras especializadas de los museos, sino por uno de los iconos mediáticos de la música pop de los años 70: Barbra Streisand (Smith, G. 2002).

El 30 de marzo de 1966, la CBS retransmitió un segundo especial de la artista, titulado Color Me Barbra, en un momento en el que la televisión comenzaba a ser un potente instrumento de uniformidad cultural. Este trabajo se había rodado al cincuenta por ciento en el Museo de Arte de Filadelfia. En él, la cantante aparecía paseando, bailando o recorriendo el espacio del museo, y causó una gran conmoción, al dar a entender que el arte ya no era ese objeto de adoración y reverencia de hombres cultos de clase alta. En Color Me Barbra, mientras recorre el museo, la cantante elige algunos cuadros y se va transformando en los personajes representados en las obras: es la modelo de Modigliani, es Nefertiti en una tumba egipcia, es la reina María 
Antonieta... todo ello con un aire que no deja de ser irónico. La estrategia artística que pone en juego es la asociación de ella misma con el arte, rompiendo la barrera de la contemplación a la que es sometido el espectador del museo. Encarna así una idea nueva de que el museo puede ser virtualmente un lugar donde podemos sumergirnos, donde podemos entrar y salir a nuestro antojo, un espacio que metafóricamente puede recorrerse formando parte de la creatividad en sí misma. El arte se puede poner y quitar como un vestido, se puede "usar" para los fines individuales, destruyendo el destino final y trascendente del arte.

Que los museos, las exposiciones, los ciclos de conferencias, la música clásica de hoy día sueñen con extender el proceso viral que consiga atraer a sus salas al mayor número de visitantes, es una señal de que quiere competir por el ocio y los recursos económicos de sus usuarios en un entorno masificado de "cultura" e "información", construyéndose como "mega-eventos" o fabricando una serie de materiales de merchandising que a veces superan los beneficios obtenidos por las entradas. Por ejemplo, sólo en la librería del Louvre de París se facturan 29 millones de dólares, con tres millones y medio de visitantes al año. O el Guggenheim de Bilbao que desde su inauguración en 1997 hace que la ciudad reciba un millón y medio de turistas que generan 560 millones de dólares de beneficio económico. (Moraes, D. 2007: 27) El problema, no es que se produzcan visitas masivas, sino que se frivolice el sentido del arte y todo se convierta en "fashion". El propio arte de mujeres en algunos casos se ha visto afectado por este fenómeno. Cuando escuchamos decir que "las mujeres están de moda" es algo positivo para la difusión del arte, pero siempre surge el temor de que no exista la deseable perspectiva de género que haga visible la reivindicación de las mujeres artistas de estar en igualdad de condiciones con los artistas varones en los museos. Además, en muchos casos las artistas feministas más militantes se han posicionando en contra de todo aquellas estructuras (incluidas las económicas) que favorecen el sexismo, el racismo o el tráfico de influencias en el mundo del arte. (Guash, A. M. 2000).

Además, no es extraño que muchas de las artistas a partir de los años setenta, hayan tenido relación con los medios de comunicación, o bien como fuente o estrategia para difundir su obra (Jenny Holzer, 1950), o bien como base creativa, como es el caso de Barbara Kruger (1945) que trabajó como diseñadora en Vogue y Mademoiselle, y que en 1977 colaboró en un colectivo interesado en las influencia del arte en la cultura popular, para platear cuestiones como el aborto, la intolerancia religiosa o la libertad de expresión. La relación con los medios de masas, implica una relación con el dinero, y esa es precisamente la crítica que se ha hecho a las artes visuales, que algunos autores han señalado como menos adecuados para hablar de la "condición humana" precisamente porque se desarrolla en una "infausta proximidad con el dinero" (Vittese, A. 2012: 22), al considerar que lo más importante no es 
cuánto cuesta la obra en sí misma, si no a cuántos espectadores conseguirá captar para una exposición, valiéndose de las estrategias más variopintas.

\section{LADY GAGA Y MARINA ABRAMOVIC, O CÓMO SER MÍTICAS Y ALTERNATIVAS AL MISMO TIEMPO.}

La relación comercial entre Lady Gaga y Marina Abramovic se interpreta a través de lo que Lipovetsky (2006) ha calificado como sociedad hipermoderna, entendida como un período en el que se consolidan tendencias posmodernas que ya existían al menos desde la popularización de la televisión, como la obsesión por la imagen, la repetición de signos, la obsolescencia cada vez más rápida de objetos y símbolos, la globalización económica y la trans-territorialidad. Los rasgos distintivos de la hipermodernidad se concretan en el desarrollo de una sociedad lúdica cuya producción más importante son las industrias del entretenimiento, con las que el mundo de la producción artística está colaborando activamente. Los productos culturales necesitan y se alimentan del arte que ha pasado a dominar la economía del ocio. Frederic Martell (2012) citando a Joe Nye y su concepto de soft power afirma que “... la cultura norteamericana está en el corazón mismo de ese poder de influencia tanto si es high como si es low, tanto en el arte como en el entertainment, tanto si se produce en Harvard como si se produce en Hollywood».

El arrollador éxito de las propuestas creativas de Lady Gaga, nos sitúa frente a las paradojas de un sistema cultural hoy día traspasado por las nuevas formas de interactuar con las nuevas tecnologías. La primera paradoja es el hecho de que su éxito popular en la cultura mainstream no sólo ha impedido su éxito en la cultura académica, sino que incluso lo ha incrementado, hasta el punto de que el mundo académico le rinde sentidos homenajes a su trabajo. Su nombre es una "marca de hipermodernidad", un símbolo que funciona en realidad como una metonimia de las últimas tendencias filo-sociológicas que hablan de las cambiantes identidades posmodernas. Es curioso encontrar títulos de artículos académicos (sólo por citar algunos) como "Cuerpo y transgresión: de Helena de Céspedes a Lady Gaga" (2011) para hablar de la figura de los hermafroditas en la historia, "Lady Gaga and the Civil Religión" (2011) ${ }^{6}$ para hablar de ética o el libro sobre Teoría Queer de J. J. Halberstam (2012) titulado Gaga feminismo. Sex, gender, and the end of normal, por no hablar de que se ha convertido, por supuesto, en el objeto favorito e ineludible de la moderna "Sociología de la Fama". Y no se trata de un objeto de estudio más al que

\footnotetext{
5 De Begoa Enguix en la Revista Latinoamericana de Estudios sobre Cuerpos, Emociones y Sociedad. № 5 . páginas 25-38.

${ }^{6}$ De Frederick Turner en Simposium: Taming the Sabage Mind. No 48. págs. 495-497.
} 
los Estudios Culturales dirigen su mirada, basta comprobar cómo muchas veces estos textos poco tienen que ver con la cantante y su obra.

La segunda paradoja tiene que ver con el antiguo antagonismo planteado en la teoría clásica entre el espectáculo de masas y el arte culto. Desde su debut con su primer álbum en el año $2008^{7}$, el éxito de público de Lady Gaga no ha parado de aumentar: algunos de sus discos han sido los más vendidos del mundo. Sus apariciones públicas son siempre un espectáculo a comentar por la prensa mundial, y en su corta carrera en el tiempo ha acumulado incesantemente los premios más importantes de música pop ${ }^{8}$. Lady Gaga se vende a sí misma no sólo como una cantante o una compositora más, sino como una creadora que se mueve en el nuevo terreno ambiguo desarrollado entre la alta cultura y la cultura mainstream. Vendedora de discos, pero también realizadora de elaboradas performances, su estética cambiante recuerda la obra de la fotógrafa Cindy Sherman cuya obra ha consistido en fotografiarse a sí misma mientra representa distintas identidades sociales, distintas formar de ser mujer a lo largo de la historia y de la realidad social.

No sabemos cómo es Cindy Sherman en su vida cotidiana, tampoco sabemos cómo es Lady Gaga. Incluso en sus apariciones desnuda o sin maquillar ante la cámara, da la sensación de estar construyendo una máscara más puesta en función de un significado más general y trascendente que parece querernos transmitir en cada aparición pública. Y todo consigue hacerlo sin que parezca una "gran transgresora" del orden social, aunque se vista con un vestido y un tocado que parece carne cruda" o llevando un traje de novia mientras camina por un aeropuerto, no altera las normas de la feminidad en los medios de masas, que exigen siempre una auto-representación del cuerpo femenino construido como un espectáculo que captura la mirada del espectador hipnotizado por la extrañeza, lo extravagante o lo sofisticado de un cuerpo que no abandona nunca la voluntad de significar.

La tercera paradoja es la producida entre la exaltación de la individualidad propia de la Modernidad (representada en la idea de 'genio' creador que la crítica feminista tanto ha cuestionado), y la valoración de la obra colectiva que se produce al mismo tiempo que la "muerte del autor". En el tratamiento que hace la prensa de Lady Gaga se ve claramente la contradicción que señala Vitesse (2012:26) cuando dice que, mientras que en la realidad del arte contemporáneo la obra se ha ido convirtiendo en

\footnotetext{
${ }^{7}$ Me abstengo de proporcionar detalles excesivamente prolijos sobre el trabajo musical de Lady Gaga que están accesibles en Internet y que, aunque son importantes, no son el objeto de nuestra exposición.

${ }^{8}$ Por ejemplo, cinco premios Grammy, trece MTV, y las revistas Time y Forbes le han incluido en las listas de personas más influyentes en el mundo.

${ }^{9}$ El famoso vestido exhibido en el año 2010 formará parte de la colección del Museo Nacional de Mujeres en el Arte de Washington D.C. (Según la CBS News del 29 de enero de 2013).
} 
un proceso colectivo, paralelamente se ha desarrollado una exaltación del ego, de la individualidad necesaria al público de masas que debe convertir en mito, en símbolo trascendente, a la individualidad que se supone detrás de todo proceso creativo, de la forma más clásicamente romántica. Lady Gaga compone sus canciones, interviene en el diseño de sus espectáculos, decide dónde intervenir de manera política apoyando una determinada causa social, pero sus espectáculos no existirían sin un entramado industrial propio de la fabricación de los espectáculos mediáticos, que no tienen nada que ver con "lo popular", sino con una industrial altamente especializada.

Es curioso cómo en la crítica académica tendemos a interpretar los valores simbólicos de lo que su obra representa, olvidando todo lo que su éxito ha tenido que ver con el desarrollo de una gran estrategia de marketing desarrollada por Los Premios Grammy. En el año 2009, los organizadores de estos premios se dieron cuenta que sólo el 14\% de los espectadores que seguían el evento televisivo tenían entre 18 y 49 años, y los anunciantes asociados a este premio, comenzaron a cuestionarse seguir invirtiendo en él. Para hacerse con un público más joven, para los premios del 2010 la empresa confió en la empresa de marketing integrado, TBWA/Chiat/Day, que diseñó una campaña llamada We're All Fans que cubría los medios tradicionales como la televisión, pero también las nuevas tecnologías. La compañía desarrolló un programa a través del cual los fans podían incluir frases impactantes que permitían elaborar un mosaico además de los artistas favoritos. Por otra parte, la agencia intentó atraer a algunos artistas, que en su mayoría eran escépticos frente a Internet, y que temían que la difusión de la música gratuita perjudicase sus ventas. Lady Gaga fue una de las primeras que aceptó intervenir en la campaña de TBWA/Chiat/Day anunciando en la web y en televisión la campaña We're All Fans. El video promocional de los Premios con la artista se subió a YouTube obteniendo un éxito arrollador en Twitter, Facebook y MySpace y fue visto dos millones de veces durante las semanas antes de la celebración de los premios.

Otro rasgo de la contradictoria hipermodernidad es lo que tiene Lady Gaga de trascendente y de banal al mismo tiempo. De la misma forma que aprovecha la estética publicitaria y de video-clip donde su cuerpo aparece hiper-feminizado y expuesto a la mirada pública o se permite aparecer vestida hombre representando su alter ego masculino, ha sabido convertirse en un icono de la marginación y la incomodidad adolescente frente al mundo adulto, apoya la causa gay, e incluso juega a la ambigüedad entre el feminismo y la indiferencia militante. Se atreve además a citar en sus vídeos elementos religiosos, que son criticables por ciertos colectivos, pero al mismo tiempo, digeribles por el grupo social porque no juega a atacarlos directamente, sino a atizarlos de una forma irónica y por lo tanto distanciada. Ella representa en su polémico vídeo Judas a María Magdalena y aparecen figuras como Jesucristo o Judas sin que resulte del todo creíble. 
Por fin, si por algo se puede definir la hipermodernidad es por la fabricación de nuevos públicos con instrumentos que no existían con anterioridad: los modelos de comunicación peer to peer, la "economía del regalo" (gift economy), el marketing viral... todo ello ha situado a los espectadores como agentes de producción de cultura al mismo tiempo que la consumen. El fenómeno "fan" pasa a ser, no sólo una parte de la industria cultural, sino la fundamental, y los artistas cuentan con ellos para formar sus propias obras. Lady Gaga es sin duda la artista que mayor éxito ha conseguido en la utilización de estas nuevas redes. En el año 2012 era la persona en el mundo con más seguidores en Twitter (trece millones), y el disco que se anuncia para noviembre de 2011, ARTPOP, ha sido planificado para ser distribuido de forma viral. Lady Gaga posee el capital más importante en la hipermodernidad que son los fans y seguidores que participan en todas sus propuestas de forma apasionada en universo saturado de información. En unas declaraciones a The Guardian explicó que ARTPOP es más que un disco, es una "experiencia multimedia" y que se le servirá al público acompañado de una aplicación para iPad, iPhone, etcétera, y que "será completado con charlas, películas para cada canción, música adicional, contenido, juegos, actualizaciones de moda, revistas..."10

Lady Gaga es un personaje profundamente polifacético. Sus dotes comerciales se ponen en funcionamiento cada vez que lanzar un disco, comercializa un perfume, escribe críticas de moda o hace de modelo o actriz. Pero esa faceta comercial está profundamente interrelacionada con otra espiritual y trascendente, en la que confiesa que toda su vida es "de servicio a mis fans", y que todas sus creaciones colectivas están dirigidas a conseguir efectos estéticos sobre ellos otorgándoles la cualidad de ser una masa pensante y creativa: "Quiero que la imagen sea tan fuerte que los fans quieran comer, saborear y lamer cada parte de nosotros."11 En 2001 envió una frase del gurú Osho por Twitter a sus 15 millones de seguidores: "la mayor forma de rebelión es la creatividad", borrando una vez más la diferencia entre la cultura pop y la espiritualidad sincrética típica de la posmodernidad. Al mismo tiempo, Lady Gaga ofrece a sus fans en sus videoclips, concebidos como si fueran pequeñas películas, un coctel de los elementos básicos de la cultura mainstream: el sexo, la violencia y el poder. En muchos casos también se representa el poder de los varones sobre el cuerpo de las mujeres, eso sí, con la consabida ambigüedad de Lady Gaga que puede decir que rechaza el feminismo, al mismo tiempo que se declara "un poco feminista" y que desea representar a las mujeres como "sexualmente poderosas". Es la mujer más influyente en Internet, y al mismo tiempo consigue parecer míticamente alternativa y conectar con sus fans a través del sentimiento adolescente de sentirse raros, marginados o "monstruos" como ella denomina a sus fans.

\footnotetext{
${ }^{10}$ The Guardian, 5 de febrero de 2013

${ }^{11}$ Citado por Chris Harris en MTV, 9 de junio de 2006.
} 
Su frivolidad se alterna además con su filantropía, eso en lo que parecen haberse convertido las reivindicaciones políticas para mucha gente en la era contemporánea. Pueden no existir los grandes ideales de justicia e igualdad vinculados a un proyecto político más general, pero siguen existiendo las acciones puntuales en reivindicación de ciertos colectivos. Lady Gaga ha sido muy activa en este sentido. Ha dado conciertos para recaudar fondos para Haití en el 2010, diseñó una pulsera para recaudar dinero tras el tsunami de Japón en el 2012 y declaró el deseo de donar dinero para apoyar a las víctimas del Huracán Sandy, además de apoyar campañas de Unicef en contra del acoso escolar y la lucha contra el sida y el apoyo a la comunidad LGBT en la que es considerada un icono gay, entre otras cosas por haber declarado su bisexualidad. Todo ello se ha completado con la fundación de Born This Way Fondation (BTWF) fundada en el 2011 y que tiene como objetivos trabajar por el empoderamiento de la juventud, la lucha contra el acoso escolar y contra la anorexia y la bulimia.

Lady Gaga involucra así de un modo total a su público en todas sus campañas, en una amalgama de objetivos que van de la venta de discos a la filantropía, del arte como elemento crítico en el sistema a la adaptación absoluta y disciplinada a la exigencia mediática de aparecer hipersexualizada, de la parodia de la religión cristiana a la exaltación de la espiritualidad oriental tan de moda en occidente en los últimos años. No hay límite en la representación de lo paradójico. La "atención desatenta" que generan las nuevas tecnologías, el contacto rápido y perecedero entre los fans y las estrellas, se ha convertido en la fuente de poder de Lady Gaga.

Por su parte, Marina Abramovic (Belgrado, 1946) es una de las artistas contemporáneas mundialmente más conocidas. Ha desarrollado un trabajo constante desde los años setenta, en un negocio del arte que dificulta la permanencia a través del tiempo de las mujeres como creadoras. Abramovic tuvo una formación universitaria clásica en Bellas Artes, y sus primeras exposiciones públicas se realizaron en un contexto creativo donde la performance era el producto de más éxito en el mundo del arte. En sus primeras intervenciones, Abramovic utilizaba el cuerpo como elemento artístico, interesada sobre todo en investigar sobre los estados de conciencia, tema que marcó el futuro de su trabajo ${ }^{12}$. Durante treinta años, ha conseguido mantener una gran productividad, y a partir del año 2010 se ha convertido en una de las artistas más conocidas en el mundo, año en el que el MOMA organizó una retrospectiva suya en la que participó con la performance más larga que se había

\footnotetext{
${ }^{12}$ No podemos hacer de este texto una recopilación sistemática de sus obras, pero sí queremos dejar referencia por ejemplo de algunas de sus primeras performans de los años setenta, todas calificadas como "Ritmo" con numeraciones (10, 5, 2, 0) desarrolladas entre 1973 y 1974. En ellas podía cortarse, quemarse o tomar pastillas para causarse un estado de catálisis, llegando incluso a permitir que el público la agrediese con distintos objetos.
} 
hecho nunca. Estuvo sentada 716 horas en una mesa a la que, por turnos, podían ir sentándose frente a ella los espectadores. Este año 2013 se estrenó un documental con el título de la exposición dirigido por Matthew Akers titulado La artista está presente que ha recibido el reconocimiento de varios premios en festivales internacionales. Sus trabajos han sido además objeto de la crítica académica que se he dedicado a desentrañar el sentido de su obra en cuanto al uso del cuerpo como elemento artístico $^{13}$. La exposición del MOMA supuso para Abramovic un reconocimiento público sin precedentes sobre todo porque, tal como ha reconocido, le ha supuesto el acercamiento a un público joven al que no tenía acceso anteriormente. Reconoce que la mayor fama mundial le ha llegado a los sesenta y cinco años. En una conversación con Ricardo Tisci, diseñador de la casa Guivenchi, afirmaba que parte de este éxito se lo debe a Lady Gaga que fue a ver su retrospectiva y, aunque no llegó a sentarse frente a ella porque había mucho público, Abramovic se dio cuenta de que a su alrededor había jóvenes de doce, catorce o dieciocho años que se interesaron por su trabajo gracias a su visita. Eso le hizo ganar nueva audiencia. Lanzó así su carrera al meinstream y eso cambió su vida completamente.

Marina Abramovic ha conseguido un gran éxito de público lo que a su vez le ha permitido entrar en los circuitos del los grandes espectáculos de masas queno han perdido el reconocimiento de la Alta Cultura. De ser una artista alternativa de los años setenta se ha transformado en una artista reconocida en los circuitos de más alta cultura, como los espectáculos de opera. En el año 2012 presentó un espectáculo en el Teatro Real de Madrid, Vida y muerte de Marina Abramovic, una ópera que había sido estrenada en el Mánchester en el año 2011, dirigida y creada por el director americano Robert Wilson. La obra es narrada por Willem Dafoe y parte de la música fue desarrollada y cantada por el artista transgénero Anthony Hogart. Esta obra es muy significativa porque supuso el desarrollo de un terreno intermedio entre la baja y la alta cultura.

\section{CONCLUSIONES}

No podemos ver esta relación entre Lady Gaga y Abramovic como interesada, sino una muestra de cómo han ido evolucionando tanto el mercado del arte como la cultura pop. Ambos elementos se conjugan intercambiando valor simbólico y valor comercial, en un entorno donde el entretenimiento es el motor de la economía. Algunos teóricos relacionan el éxito de los famosos con las ansiedades propias de un determinado contexto social en el que un determinado personaje adquiere la fama. La estética de Lady Gaga apela a una nueva forma 'hipermoderna' de las personas y los

\footnotetext{
${ }^{13}$ Vid. por ejemplo DEMARIA, C. 2004
} 
grupos de organizar su tiempo entorno a los períodos de trabajo y de diversión asociada de forma constante a las nuevas tecnologías (Corona, V. P. 2011: 727). Los fans pueden escuchar música o ver videos de sus ídolos, participar en Twitter o Facebook o participar de distintas formas en las propuestas de las páginas web de sus artistas favoritos.

Es evidente que el consumo cultural puede leerse como un "sistema de recompensas" 14 (Crane, D. 2012: 113) que obtienen los consumidores cuando compran una exposición, una canción o ven una película. En el sistema de alta cultura "las recompensas simbólicas eran más importantes que las recompensas materiales, a diferencia del sistema de recompensa de la cultura popular -como el cine, la televisión o la música comercial-, en el que la recompensas materiales eran más importantes que las recompensas simbólicas" en referencia a Bourdieu (1993). Sin embargo, las recompensas obtenidas por el consumo de Alta cultura se ha visto altamente desestabilizado precisamente por la inclusión de la cultura pop en el gran arte, sobre todo con artistas que toman precisamente elementos totalmente banales de la cultura mediática y los convierten en objetos de su arte como Damien Hirst, Jeffrey Koons, Richar Price o Takashi Murakami quien, por ejemplo, en su retrospectiva montada en el Brooklyn Museum of New York, incluía una tienda real de Louis Vuiton que vendía bolsos diseñados por él.

Esto es una muestra no sólo de que se han desdibujado las fronteras entre el Arte y la cultura popular, sino entre el Arte en sí mismo y el negocio. Algunos teóricos como Michael Findlay (2013: 43) dicen por que "hace un siglo, la mayoría de los marchantes eran tenderos enaltecidos. Ahora, algunos son empresarios de la celebridad", creándose una relación entre arte, moda y negocio ${ }^{15}$.

Terry Egleton (2001: 84) cuando reflexionaba sobre los cambios culturales ocurridos en la posmodernidad, argumentaba que en la cultura se escenificaban conflictos sociales que el denomina "guerras culturales" donde los grupos o etnias compiten por dar visibilidad a los textos que producen. Sin embargo, hoy en día,

${ }^{14}$ El "sistema de recompensas" se refiere a la idea de que cuando consumimos algún objeto o bien cultural, no sólo compramos elementos prácticos que nos sirven de forma instrumental para algo (divertirnos, emocionarnos, por ejemplo), sino que compramos todos los valores culturales asociados a esos productos. Por ejemplo, podemos pensar en los "premios" tan diferentes que como espectadores podemos obtener por el hecho de ir a ver al cine una comedia, o asistir a una función de ópera clásica. En la primera podemos obtener directamente una sensación de simple "diversión", mientras que en la segunda recibimos una recompensa más "intelectual" en el sentido de que nos hace sentir parte de una élite cultural, de un "grupo de elegidos" que se destacan del gran público.

${ }^{15}$ El autor hace referencia al acuerdo entre el Museo de Arte Contemporáneo de los Ángeles y la marca francesa de artículos de lujo LVMH, que instaló una tienda en el museo con objetos diseñados por artistas como Murakami o Marc Jacobs. (Findlay, M. 2012:178) 
señala que lo "refinado" puede ser comercial y que los productos "de masas" pueden ser también radicales. Sin embargo, señala, la alta cultura es hoy en día ideológicamente mucho menos influyente que la cultura popular.

La simbiosis entre la cultura mediática y la alta cultura, la necesidad que una tiene de la otra en los circuitos comerciales, se puede estudiar en lo que ha sido la fulminante carrera de Lady Gaga pero también en la dilatada carrera de Marina Abramovic. Es un símbolo de una época que Lady Gaga haya realizado una performance en el Museo de Arte Contemporáneo en Los Ángeles luciendo el primer sombrero diseñado por el arquitecto Frank Gehry (Corona, V. P., 2011: 725) sobe un piano decorado por el artista Damien Hirst. Pero también lo es que Abramovic se fotografíe con un jersey de Givenchy diseñado por Ricardo Tisci con la palabra "favelas", supuestamente denunciando los problemas de marginación y desigualdad que todavía se mantienen en el mundo con todo lo contradictorias que puedan ser estas estrategias publicitarias.

Lady Gaga afirma en su web que "La cultura Pop es arte" haciendo una declaración de intenciones. Tanto la cultura pop como la alta cultura son compatibles y nadie debe renunciar a esta conjugación, que en el fondo, significa que el reconocimiento de que el gran Arte que aporta capital simbólico, según el concepto de Bourdieu, puede estar incluso controlado por una bohemia de vanguardia que pertenece a la cultura pop. En una ocasión ella afirmó: "Me esfuerzo por ser una Warhol femenina. Quiero hacer cine y música, fotografía y pintura también. Hacer moda. Hacer grandes instalaciones en museos. Me gustaría ser probablemente más mediática que él -combinando medios e imágenes y haciendo arte interactivo" (Corona, V.P. 2011: 731).

Abramovic también ha querido sin duda hacerse con el prestigio aurático del estrellato mediático de los últimos tiempos en los que las estrellas parecen sustituir los valores religiosos y trascendentes de las religiones tradicionales, en el sentido que son capaces de aportar un escape al tedio y la rutina de la vida diaria, y además funcionan como un vínculo social. El deseo de culto a los famosos no ha parado de aumentar en los últimos tiempos, en momentos de incertidumbre donde se necesitan más que nunca figuras que representen el vínculo de unión necesario para el bienestar psicológico y social de las personas. En su "Manifesto of Little Monster" Lady Gaga declara que "es en la teoría del la percepción donde establecemos nuestros vínculos (...) No somos nada sin nuestra imagen. Sin nuestra proyección. Sin el holograma espiritual de quien percibimos que somos o de lo que nos transformaremos en el futuro". 


\section{BIBLIOGRAFÍA}

BUCK-MORSS, Susan (2004) Mundo soñado y catástrofe. La desaparición de la utopia de masas en el Este y el Oeste, Madrid, La Balsa de la Medusa.

BENJAMIN, Walter (1989): Discursos ininterrumpidos I. Buenos Aires. Taurus.

BERARDI, Franco (2003): La fábrica de la infelicidad: nuevas formas de trabajo y movimiento global, Madrid, Traficantes de Sueños.

BERNÁRDEZ RODAL, Asunción (2011): «Arte posmoderno, ¿arte feminista? Cuerpo y representación en la sociedad de la información», en Fernández Valencia, Antonia y López Fdez. Cao, Marián (ed.), Contar con el cuerpo: construcciones de la identidad femenina. Madrid. Fundamentos: pp. 123-150.

BOURDIEU, Pierre (1991): El sentido práctico, Madrid, Taurus.

BOURDIEU, Pierre (1995) La distinción. Criterios y bases sociales del gusto. Madrid, Taurus.

CORONA, Victor P. (2011) "Memory, Monsters, and Lady Gaga" en The Journal of Popular Culture, Vol. 46, No 4. Págs. 725-743

DEMARIA, Cristina (2004) "The Performative Body of Marina Abramovic: Rerelating (in) Time and Space" en European Journal of Women's Studies, $\mathrm{n}^{\circ} 11$ (3), págs. 295-307.

DE MORAES (2007):"La tiranía de lo fuga: mercantilización cultural y saturación mediática" en Sociedad mediatizada, Denis de Moraes (Coord.), Madrid, Gedisa

EGLETON, Terry (2001) La idea de cultura. Una mirada sobre los conflictos culturales, Barcelona, Paidós.

FINDLAY, Michael (2 012) El valor del arte. Dinero, poder y belleza, Barcelona, Fundación Salvador Dalí.

HALBERTAN, J. Jack (2012) Gaga Feminism. Sex, gender, and the end of normal, Boston, Bacon Press.

HANNA, Richard, ROHM, Andrew, CRITTENDEN, Victoria L. (2011) "We're all connected: The power of the social media ecosystem", en Businesss Horizons, BUSHOR-881.

HUYSSENS, Andreas (2002) Después de la gran división. Modernismo, cultura de masas, posmodernismo, Buenos Aires, Adriana Hidalgo Ed.

GUASCH, Anna María, El arte último del siglo XX. Del posminimalismo a lo multicultural, Madrid, Alianza, 2000

LIPOVETSKY, Gilles (2006) Los tiempos hipermodernos, Barcelona: Anagrama, D.L. 2006.

MARTEL, Frederic (2012), Cultura mainstream. Cómo nacen los fenómenos de masas, Madrid, Santillana.

MORAES, Denis (2007) "La tiranía de lo fugaz: mercantilización cultural y saturación mediática" en Moraes, Deniís Sociedad mediatizada, Barcelona, Gedisa. Págs. 21-38.

POLLOCK, Griselda (2010): Encuentros en el museo feminista virtual: tiempo, espaciy el archivo. Madrid. Cátedra.

SMITH, Greg (2002) "Streisand Shops the Museum Store: Consuming Art on Television" en Journal of Popular Film \& Television, Vol. 30. Fasciculo 1.

VETTESE, Angela (2012) El arte contemporáneo. Entre el negocio y el lenguaje, Madrid, Rialp. 